\title{
AVALIAÇÃO DA HABILIDADE DE INFERÊNCIA EM LEITURA: ESTUDO DE CASO COM UMA QUESTÃO DA PROVINHA BRASIL
}

\author{
Fábio José Rauen
}

Resumo: A Provinha Brasil visa avaliar o nivel de alfabetização de estudantes brasileiros no $2^{\circ}$ ano do Ensino Fundamental. Em 2009, houve duas ediçöes: no início do ano para avaliar o processo de alfabetização e no final do ano para identificar avanços e limitações. Entre as habilidades avaliadas pelo teste, destaca-se a de inferir a partir da leitura de textos. Na segunda edição de 2009, a vigésima questão deu conta desse descritor, utilizando-se de uma história em quadrinhos de Mauricio de Sousa. Motivado pela dispersão de respostas dadas à questão por dez alfabetizadoras na dissertação de Nazário (2010), analisam-se nesse artigo, com base na Teoria da Relevância, a proposição e as opções de resposta. Fundamentado nos achados, destacam-se as dificuldades para o desenvolvimento de alternativas objetivas para questões inferenciais, dado que inferências mais sofisticadas e diferentes graus de força das suposições cognitivas entram em cena na interpretação.

Palavras-chave: Cognição. Inferência. Relevância. Teoria da relevância. Provinha Brasil.

\section{INTRODUÇÃO}

O objetivo da Provinha Brasil é diagnosticar o nível de alfabetização dos alunos do $2^{\circ}$ ano do Ensino Fundamental para viabilizar intervenções corretoras quando necessário. Em 2009, a Provinha Brasil foi aplicada em duas edições. A primeira edição, no início do ano letivo, avaliou o processo de alfabetização. A segunda edição, no final do ano letivo, comparando o desempenho dos alunos com a primeira avaliação, visou identificar progressos e limitações.

Entre os descritores do eixo de avaliação das habilidades de leitura observados pelo instrumento, destaca-se o de inferir informação. $\mathrm{Na}$ segunda edição de 2009 da Provinha Brasil, com base em uma história em quadrinhos de Maurício de Sousa, a vigésima questão é dedicada a essa habilidade.

\footnotetext{
* Doutor em Letras/Linguística pela Universidade Federal de Santa Catarina (UFSC). Docente e Coordenador do Programa de Pós-graduação em Ciências da Linguagem da Universidade do Sul de Santa Catarina (UNISUL). E-mail: fabio.rauen@unisul.br.
} 
Com o objetivo de avaliar competências e habilidades necessárias de docentes alfabetizadoras para a análise crítica de questões da Provinha Brasil, Nazário (2010) selecionou onze questões do instrumento e, entre outras tarefas, solicitou a dez alfabetizadoras que as respondessem. As docentes responderam adequadamente todas as questões selecionadas, exceto aquela dedicada à inferência, cujo desempenho revelou significativa dispersão. Em função dessa consecução, analisa-se no presente artigo a proposição e as opções de interpretação da vigésima questão com base no aparato descritivo e explanatório da Teoria da Relevância, destacando a dificuldade de se elaborarem alternativas de respostas em questões desse tipo.

Para dar conta desse objetivo e, desse modo, tentar avaliar por que houve essa dispersão nas respostas das docentes, o presente texto foi dividido em mais quatro seções. $\mathrm{Na}$ segunda seção, faz-se uma breve revisão sobre a Teoria da Relevância com base em Rauen (2005, p. 3537). Na terceira seção, apresenta-se em linhas gerais a Provinha Brasil, destacando seus objetivos e sua metodologia. Na quarta seção, analisamse a proposição e as opções de resposta da vigésima questão da segunda edição de 2009 da Provinha Brasil. Na quinta seção, por fim, apresentam-se as considerações finais.

\section{BREVE REVISÃO SOBRE TEORIA DA RELEVÂNCIA}

Conforme Sperber e Wilson (1986, 1995), a Teoria da Relevância está fundamentada em dois princípios gerais: o princípio cognitivo de que a mente humana dirige-se para a maximização da relevância e o princípio comunicativo de que enunciados geram expectativas precisas de relevância. ${ }^{1}$

Por relevância define-se uma função entre efeitos cognitivos a serem maximizados e esforços de processamento a serem minimizados. Relevância é uma propriedade dos inputs (enunciados, pensamentos, memórias, percepções sensoriais, etc.) que são direcionados aos processos cognitivos. Na medida em que se processa um input num

\footnotetext{
${ }^{1}$ Devido a constrições de espaço, o que se faz neste artigo é tão somente apresentar alguns dos conceitos centrais da Teoria que se julgam essenciais para a compreensão da análise da dispersão de respostas à vigésima questão da Provinha Brasil. Para uma leitura mais substantiva, leiam-se Sperber e Wilson (2001, 1995, 1986), Wilson (2004) ou Silveira e Feltes (2002).
} 
contexto de suposições cognitivas que se encontram disponíveis para um indivíduo, esse input pode gerar algum efeito cognitivo modificando ou reorganizando essas suposições.

Esse input pode fornecer evidências que: a) fortalecem suposições existentes; b) contradizem ou enfraquecem suposições existentes; ou c) derivam implicações contextuais, nesse caso, conclusões que são obra da combinação do input com o contexto cognitivo, mas que não surgem nem do input nem do contexto isoladamente.

Sperber e Wilson propõem que, em contextos iguais, quanto maiores forem os efeitos cognitivos obtidos do processamento de um imput, maior será sua relevância. Visto que a geração de efeitos contextuais implica investimento energético, os autores propõem que, em contextos iguais, ao ser menor o esforço de processamento, maior será a relevância.

Posto isso, conforme o princípio cognitivo de relevância, os recursos cognitivos são direcionados para as informações que parecem mais relevantes ao indivíduo. Conforme o princípio comunicativo de relevância, um falante/escritor, pelo próprio ato de dirigir-se a um ouvinte/leitor, gera uma expectativa de relevância ótima. Um enunciado diz-se otimamente relevante quando ele é suficientemente relevante para merecer ser processado e quando ele é o estímulo mais relevante que o falante/escritor se dispôs a ou foi capaz de produzir.

Considerando que o ouvinte/leitor pretende obter uma interpretação que satisfaça sua expectativa de relevância ótima, baseado na codificação linguística, ele deve enriquecer esses inputs para obter um significado explícito e, eventualmente, seguindo uma rota de esforço mínimo, obter um significado implícito com base nesse significado explícito, terminando o processo quando a interpretação se conforma com sua expectativa de relevância.

Veja-se:

Processo teórico da compreensão com base na relevância.

Siga um caminho de esforço mínimo na computação de efeitos cognitivos: 
a) considere hipóteses interpretativas (desambiguações, atribuições de referência, suposições contextuais, implicaturas, etc.) seguindo a ordem de acessibilidade;

b) pare quando é alcançado o nível esperado de relevância. (WILSON, 2005, lição 4, p. 7, tradução própria).

Segundo a Teoria da Relevância, a forma linguística do enunciado encaixa-se em uma forma lógica, no mais das vezes não proposicional ou semanticamente incompleta. Essa forma lógica é então enriquecida por inferências com base em dados contextuais, de modo a se obter uma explicatura, aqui entendida como uma forma proposicional, ou melhor, uma proposição semanticamente completa para a qual se pode atribuir valor de verdade. Em alguns casos, essa forma proposicional funciona como uma premissa implicada com base na qual se gera dedutivamente uma conclusão implicada ou implicatura, nesse caso, uma proposição que possivelmente seria a interpretação última pretendida pelo falante.

Conhecidos em linhas gerais os principais conceitos da teoria da relevância e o processo teórico de compreensão guiado pela relevância, apresentam-se a seguir objetivos e metodologia da Provinha Brasil, destacando-se aspectos das edições de 2009 desse instrumento de avaliação.

\section{A PROVINHA BRASIL}

A Provinha Brasil é um instrumento de avaliação da alfabetização infantil elaborado pelo Instituto Nacional de Estudos e Pesquisas Educacionais Anísio Teixeira (Inep) com o apoio da Secretaria de Educação Básica do Ministério da Educação (SEB/MEC) e de universidades que integram a Rede Nacional de Formação de Professores do MEC. Seu objetivo é o de diagnosticar o nível de alfabetização dos alunos no início do processo de aprendizagem. Embora se reconheça que as habilidades de alfabetização e de letramento não se desenvolvem somente nos dois primeiros anos da escolarização formal, mas durante toda a educação básica, toma-se como pressuposto que a identificação e o saneamento de problemas encontrados nas fases iniciais do processo potencializam a efetiva aprendizagem dessas 
habilidades. O instrumento, desse modo, tem a finalidade última de permitir intervenções corretoras, caso se apresentem insuficiências em leitura e escrita no desempenho dos alunos.

As chamadas habilidades foram organizadas e descritas no documento Matriz de referência para avaliação da alfabetização e do letramento inicial que, por sua vez, fundamentou-se, entre outros documentos, no texto Pró-letramento - programa de formação continuada de professores dos anos/séries iniciais do ensino fundamental.

Segundo o Ministério da Educação:

As habilidades constantes na Matriz de Referência estão fundamentadas na concepção de que alfabetização e letramento são processos a serem desenvolvidos de forma complementar e paralela, entendendo-se a alfabetização como o desenvolvimento da compreensão das regras de funcionamento do sistema de escrita alfabética e o letramento como as possibilidades de usos e funções sociais da linguagem escrita, isto é, o processo de inserção e participação dos sujeitos na cultura escrita. (BRASIL, 2009, p. 12).

As habilidades indispensáveis para a alfabetização e o letramento foram agrupadas em cinco eixos fundamentais, dos quais os quatro primeiros foram considerados na segunda edição de 2009 da Provinha Brasil: apropriação do sistema de escrita, leitura, escrita, compreensão e valorização da cultura escrita, e desenvolvimento da oralidade.

O eixo da apropriação do sistema de escrita concerne à aquisição das regras que orientam a leitura e a escrita no sistema alfabético. Nesse eixo, espera-se que o estudante: compreenda os aspectos que viabilizam a comunicação escrita, domine convenções gráficas, identifique diferentes grafias de letras do alfabeto e reconheça diferentes unidades sonoras e suas respectivas representações gráficas.

O eixo da leitura envolve capacidades de decifração, compreensão e produção de sentido, incluindo capacidades que habilitam o aluno a participar ativamente de práticas sociais letradas. Para isso, espera-se que o estudante decodifique palavras e textos, reconheça finalidade ou assunto de textos com base em imagens, características gráficas do

RAUEN - Avaliação da habilidade de inferência... 
suporte ou do gênero textual, identifique informações relevantes ou realize inferências para a compreensão de textos, localize dados explícitos e realize inferências sobre o conteúdo de textos.

O eixo da escrita envolve capacidades de produção inseridas nas atividades sociais letradas, considerando objetivos, leitores e contexto delimitados. Nesse eixo, espera-se dos estudantes o desenvolvimento da escrita desde palavras com sílabas simples e complexas até frases, bilhetes, cartas, histórias, entre outros gêneros, utilizando o princípio alfabético.

O eixo da valorização da cultura escrita concerne a aspectos que permitem conhecer e valorizar formas de produção e circulação social da escrita.

Na segunda edição de 2009 da Provinha Brasil, dadas as limitações técnicas para correção de questões abertas, não foram elaboradas questões do terceiro eixo. Por fim, o quarto eixo não foi tratado isoladamente, considerando-se que as habilidades que o compõem permeiam a concepção do teste e subjazem à elaboração das questões de leitura. Em outras palavras, foram consideradas apenas questões relacionadas diretamente aos dois primeiros eixos, o da apropriação do sistema de escrita e o da leitura, e indiretamente ao quarto eixo, o da valorização da cultura escrita.

$\mathrm{Na}$ metodologia de elaboração do instrumento, cada habilidade foi denominada descritor (identificado com a letra "D"). No que se refere ao primeiro eixo, o da apropriação do sistema de escrita, há três descritores: D1 reconhecer letras, D2 reconhecer sílabas e D3 estabelecer relação entre unidades sonoras e suas representações gráficas. No que se refere ao segundo eixo, o da leitura, há sete descritores: D4 ler palavras, D5 ler frases, D6 localizar informação explícita em textos, D7 reconhecer assunto de um texto, D8 identificar a finalidade do texto, D9 estabelecer relação entre partes do texto e D10 inferir informação.

A segunda edição de 2009 da Provinha Brasil foi composta de 24 questões de múltipla escolha, cada uma delas avaliando um descritor predominante (exceto o descritor D9 que não foi contemplado por questões técnicas). Conforme o caso, as quatro opções de respostas são lidas em voz alta total ou parcialmente pelo professor ou pelo aplicador ou lidas em silêncio pelos próprios estudantes. 
No que diz respeito à avaliação, os desempenhos dos alunos na Provinha Brasil são interpretados com base em cinco diferentes níveis de desempenho. Em linhas muito gerais, o nivel 1 engloba alunos que estão em um estágio muito inicial. Eles demonstram começar a apropriar-se das habilidades referentes ao domínio das regras do sistema alfabético para ler e escrever.

O nivel 2 engloba alunos que, por exemplo, associam adequadamente letras e sons, leem, mesmo com dificuldade, palavras com vários tipos de estrutura silábica, reconhecem a finalidade do texto com o apoio das características gráficas ou reconhecem o assunto de gêneros textuais mais próprios do contexto escolar.

O nivel 3 engloba os alunos que consolidaram a capacidade de ler palavras de diferentes tamanhos e padrões silábicos, conseguem ler frases com sintaxe simples e utilizam algumas estratégias que permitem ler textos de curta extensão.

O nivel 4 agrupa os alunos que leem textos simples e são capazes de interpretá-los, localizando informações, realizando inferências e reconhecendo o assunto ou a finalidade a partir da leitura autônoma desses textos.

O nivel 5 agrupa os alunos que demonstram ter alcançado o domínio do sistema de escrita e a compreensão do princípio alfabético com excelente desempenho, tendo em vista as habilidades que definem o aluno como alfabetizado.

A partir da identificação das habilidades e da medida do grau de dificuldade das questões, foram definidos quantitativos mínimos de questões que caracterizam cada nível de alfabetização e letramento inicial que as crianças demonstraram. Conforme o Ministério da Educação, as habilidades descritas no nivel 4 são as que caracterizam a consolidação do processo de alfabetização e que devem ser apresentadas ao término do segundo ano de escolarização. Em função disso, cabe a gestores e professores, com base na distribuição do número de acertos pelos níveis, avaliarem as habilidades consolidadas e aquelas por serem desenvolvidas, razão última do instrumento.

Em 2009, foram adotados os seguintes quantitativos de acertos para identificar os níveis de desempenho dos alunos: 


\begin{tabular}{|l|c|c|}
\hline Nível & $\begin{array}{c}\text { Primeira edição } \\
\text { Primeiro semestre de 2009 }\end{array}$ & $\begin{array}{c}\text { Segunda edição } \\
\text { Segundo semestre de 2009 }\end{array}$ \\
\hline Nível 1 & até 10 acertos & até 7 acertos \\
\hline Nível 2 & de 11 a 15 acertos & de 8 a 10 acertos \\
\hline Nível 3 & de 16 a 18 acertos & de 11 a 18 acertos \\
\hline Nível 4 & de 19 a 22 acertos & de 19 a 21 acertos \\
\hline Nível 5 & de 23 a 24 acertos & de 22 a 24 acertos \\
\hline
\end{tabular}

Figura 1 - Classificação em níveis de desempenho dos acertos dos estudantes nas duas edições de 2009 da Provinha Brasil.

Apresentados os objetivos e a metodologia da Provinha Brasil e destacados aspectos mais específicos das edições de 2009 desse instrumento de avaliação, a seção seguinte se destina a descrever e a explicar os supostos processos cognitivos necessários para dar conta tanto da proposição como das alternativas de respostas da questão sob análise.

\section{ANÁLISE DA QUESTÃO}

A vigésima questão da segunda edição de 2009 da Provinha Brasil, como anunciado, concerne ao eixo de habilidades de leitura e ao descritor D10 da habilidade de inferir informações do texto. Nessa questão, o documento de orientações sugere que o professor ou o aplicador somente leia a instrução que se segue, repetindo essa leitura duas vezes no máximo.

(1) Veja o texto silenciosamente e depois eu vou fazer uma pergunta.

Logo abaixo, há uma tira com dois quadrinhos de Maurício de Sousa Produções Ltda. No primeiro quadrinho, Mônica faz uma proposta para Cebolinha e, no segundo quadrinho, Cebolinha reage à proposta de Mônica. Em ambos os quadrinhos, os textos estão grafados em letras maiúsculas. 


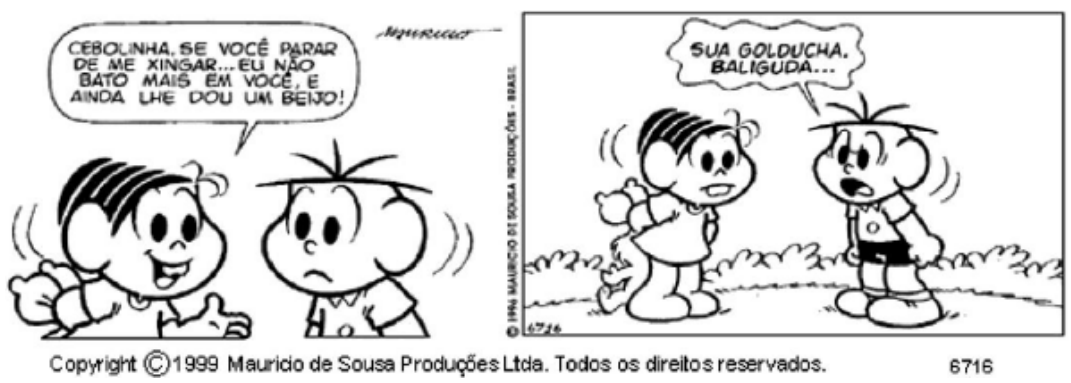

Mais abaixo, há uma pergunta e quatro opções de respostas, todas grafadas com letras maiúsculas.

(d)) Por que o Cebolinha ficou bravo com a Mônica?

(A) $\square \quad$ PORQUE ELA DEU UM SUSTO NELE.

(B) $\square \quad$ PORQUE ELA QUERIA BATER NELE.

(C) $\square$ PORQUE ELE NÃO GOSTAVA DE APANHAR DELA.

(D) $\square \quad$ PORQUE ELE NÃO QUERIA BEIJAR A MÔNICA.

Para dar conta da análise da tira, as falas de Mônica e Cebolinha serão descritas em quatro versões. $\mathrm{Na}$ versão (a), apresentam-se os elementos linguísticos das falas; na versão (b), descreve-se a forma lógica subjacente (as circunstâncias das proposições eventualmente necessárias serão indexadas por letras gregas); na versão (c), apresentam-se os preenchimentos das entradas lógicas para compor a explicatura; na versão (d), encaixa-se a explicatura numa descrição que engloba a respectiva atitude proposicional.

Além disso, será considerada a seguinte convenção na descrição e análise dos estímulos linguísticos: expressões linguísticas, quando referenciadas, são apresentadas entre aspas simples: 'beijo'; entradas enciclopédicas são apresentadas em versalete ou caixa alta: BEIJO; as referências no mundo, quando pertinentes, são apresentadas sem qualquer indicativo: beijo. 
(1a) Se você parar de me xingar... eu não bato mais em você e ainda lhe dou um beijo;

(1b) (parar de xingar x, y, z, $\left.\alpha_{\text {tempo }}\right) \rightarrow \neg$ (bater x, y, $\alpha_{\text {instrumento, }}$ $\left.\beta_{\text {tempo }}\right) \wedge\left(\right.$ dar x, y, z, $\left.\alpha_{\text {tempo }}, \beta_{\text {tempo }}\right)$;

(1c) Se você [CEBOlINHA] parar de me [MÔNICA] xingar $\varnothing$ [DE GORDUCHA E BARRIGUDA] $\varnothing$ [AGORA] $\varnothing$ [ENTÃO] eu [MÔNICA] não bato mais em você [CEBOLINHA] $\varnothing$ [COM O COELHINHO DE PELÚCIA SANSÃO] $\varnothing$ [DEPOIS] e ainda $\varnothing$ [MÔNICA] lhe [EM CEBOLINHA] dou um beijo $\varnothing$ [DEPOIS];

(1d) MÔNICA PROPÕE QUE SE CEBOLINHA PARAR DE XINGAR MÔNICA AGORA, ENTÃO MÔNICA NÃO BATERÁ MAIS EM CEBOLINHA COM O COELHINHO DE PELÚCIA SANSÃO DEPOIS E MÔNICA AINDA DARÁ UM BEIJO EM CEBOLINHA DEPOIS.

A descrição captura, em suma, a ideia de que se alguém [CEBOLINHA $\left.A_{i}\right]$ parar de xingar alguém ${ }_{j}\left[\right.$ MONNICA $\left._{j}\right]$ de alguma coisal $[\mathrm{DE}$ GORDUCHA E BARRIGUDA $A_{l}$ no tempo dessa enunciação ${ }_{t}=0$ [AGORA $A_{t}=0$ ], então alguém $\mathrm{j}_{j}\left[\mathrm{MÔNICA}_{\mathrm{j}}\right]_{\text {não baterá mais [uma vez] em alguém }}$ [CEBOLINHA ${ }_{\mathrm{i}}$ ] com algO $\mathrm{m}$ [COM O COELHINHO DE PELÚCIA SANSÃO $\mathrm{m}$ ] no tempo depois dessa enunciação $\mathrm{t}_{\mathrm{t}=1}\left[\mathrm{DEPOIS}_{\mathrm{t}=1}\right.$ e alguém ${ }_{\mathrm{j}}\left[\mathrm{MONNICA}_{\mathrm{j}}\right]$ dará algo ${ }_{\mathrm{n}}\left[\mathrm{UM} \mathrm{BEIJO}_{\mathrm{n}}\right]$ em alguém $\mathrm{i}_{\mathrm{i}}\left[\mathrm{CEBOLINHA}_{\mathrm{i}}\right]_{\text {no tempo depois dessa }}$ enunciação $\mathrm{t}_{\mathrm{t}=1}[\mathrm{DEPOIS}]_{\mathrm{t}=1}$ ainda.

Nessa descrição, percebe-se que um conjunto significativo de processos cognitivos é exigido da criança. Ela precisa correferenciar os pronomes 'você $\hat{i}_{i}$ e 'lhei' com a entrada enciclopédica CEBOLINHA como os pronomes 'mej' e 'euj' com a entrada enciclopédica MÔNICAj. Para isso, ela tem de correlacionar falante/ouvinte com o par MÔNICA $\mathrm{j}_{\mathrm{j}} / \mathrm{CEBOLINHA}_{\mathrm{i}}$ com base nas imagens dos quadrinhos e, em especial, nas convenções dos balões de fala.

Além disso, é preciso que a criança capture a correlação temporal de causa/consequência implícita na proposta de Mônica. Do ponto de vista lógico, a fala de Mônica comporta três proposições organizadas ao modo de um enunciado condicional. Como proposição antecedente, Mônica sugere que Cebolinha pare de xingá-la (P). Como proposições 
consequentes, ela sugere que não baterá mais em Cebolinha $(\neg Q)$ e que dará ainda um beijo em Cebolinha (R). Em outras palavras, se Cebolinha parar de xingar Mônica agora (num tempo que pelo menos coincide com aquele da enunciação), então será poupado de uma surra e ganhará um beijo depois (num tempo posterior ao da enunciação). Sem essa inferência, a interpretação da questão é impossível.

Ainda no que se refere às correlações temporais, há uma inferência por pressuposição na proposição antecedente. Mônica sugere que Cebolinha pare de xingá-la no tempo da enunciação. Isso pressupõe que Cebolinha xingava Mônica antes do tempo dessa enunciaçã $\mathrm{O}_{(\mathrm{t}=-1)}$.

Vale mencionar, antes de descrever as suposições em jogo, que Sperber e Wilson $(1986,1995,2001)$ propõem haver um mecanismo ou módulo dedutivo na interpretação dos enunciados que toma como imput certo conjunto de suposições e deduz todas as conclusões possíveis desse conjunto. Esse mecanismo opera de modo não trivial (sensível à força das suposições) e não demonstrativo (passível de ser confirmado, mas não de ser provado). Nesse mecanismo, os autores argumentam haver apenas regras de eliminação do tipo eliminação-e, modus ponens e modus tollens.

$\mathrm{Na}$ regra de eliminação-e, sendo consideradas em conjunto verdadeiras duas suposições $P$ e $Q$, cada uma delas é verdadeira

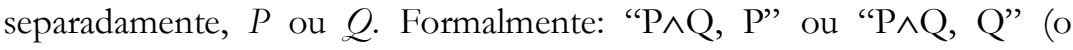
símbolo $\wedge$ equivale à operação lógica de adição).

$\mathrm{Na}$ regra de modus ponens, se há uma relação de implicação entre duas suposições $P$ e $Q$, quando a primeira é afirmada $P$, segue-se necessariamente a segunda $Q$. Formalmente: "P $\rightarrow \mathrm{Q}, \mathrm{P}, \mathrm{Q}$ " (o símbolo $\rightarrow$ equivale à operação lógica de implicação, se $\mathrm{P}$ então Q). Por vezes, é possível combinar as duas regras como é o caso da regra de modus ponens

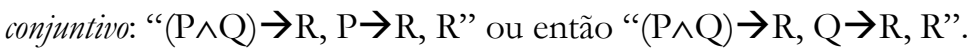

$\mathrm{Na}$ regra de modus tollens, inicia-se por um conjunto de duas alternativas $P$ ou $Q$. Em seguida, obtém-se a negação de uma delas, $\neg Q$

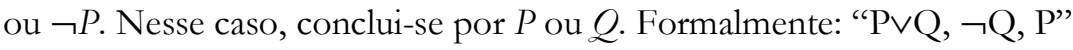

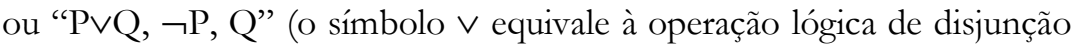
e o símbolo $\neg$ equivale à operação lógica de negação). Mais uma vez, pode-se pensar numa regra combinada, o modus ponens disjuntivo:

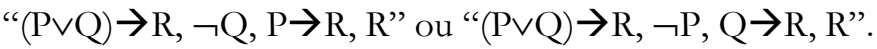


Retome-se a pressuposição:

$\mathrm{S}_{1}$ - Mônica propõe que Cebolinha pare de xingar Mônica agora (da explicatura do enunciado de Mônica);

$\mathrm{S}_{2}-\mathrm{S}_{1} \rightarrow \mathrm{S}_{3}$ (por modus ponens);

$\mathrm{S}_{3}-$ Cebolinha xingava Mônica antes (conclusão implicada).

$\mathrm{Na}$ primeira das proposições consequentes, há outra pressuposição, a de que "se Mônica sugere não bater mais em Cebolinha", é porque "ela batia nele antes".

$S_{1}$ - Mônica propõe não bater mais em Cebolinha (da explicatura do enunciado de Mônica);

$\mathrm{S}_{2}-\mathrm{S}_{1} \rightarrow \mathrm{S}_{3}$ (por modus ponens);

$\mathrm{S}_{3}-$ Mônica batia antes em Cebolinha (conclusão implicada).

Além dessas complementações, destacam-se duas outras que, embora não sejam essenciais para a criança responder à questão, poderiam ser feitas. A primeira, menos provável e, portanto, mais fraca, preenche a função de predicativo do objeto, ou seja, 'se alguém xinga alguém' esse 'alguém xinga alguém de algo'. Como se verá mais à frente, GORDUCHA e BARRIGUDA são os predicativos em jogo. Uma criança que está habituada a ler histórias em quadrinhos poderia ampliar seu ambiente cognitivo com a suposição factual $\left(\mathrm{S}_{1}\right)$ e derivar a conclusão implicada $\left(\mathrm{S}_{3}\right)$ por modus ponens.

$\mathrm{S}_{1}$ - Cebolinha sempre xinga Mônica de gorducha e barriguda (suposição factual);

$\mathrm{S}_{2}-\mathrm{S}_{1} \rightarrow \mathrm{S}_{3}$ (por modus ponens);

$\mathrm{S}_{3}$ - Mônica provavelmente pediu a Cebolinha que ele pare de xingá-la de gorducha e barriguda (conclusão implicada). 
Outra, mais factível, é a que preencheria o instrumento com o qual Mônica bateria em Cebolinha. Supostamente, trata-se do seu coelhinho de pelúcia Sansão. Essa inferência provém de duas pistas: a de que Mônica sempre bate em Cebolinha com seu coelhinho de pelúcia Sansão (factual) e a de que Mônica esconde o coelhinho de pelúcia Sansão nas costas (do imput visual).

$\mathrm{S}_{1}$ - Mônica sempre bate em Cebolinha com seu coelhinho de pelúcia Sansão (suposição factual);

$S_{2}$ - Mônica está escondendo o coelhinho de pelúcia Sansão nas costas (do input visual);

$\mathrm{S}_{3}-\mathrm{S}_{1} \wedge \mathrm{S}_{2} \rightarrow \mathrm{S}_{4}$ (por modus ponens conjuntivo);

$\mathrm{S}_{4}$ - Mônica propõe não bater em Cebolinha com o coelhinho de pelúcia Sansão (conclusão implicada).

Além da descrição da explicatura, é necessário integrá-la em um ato de fala. Conforme Sperber e Wilson (1986, 1995), enunciados representam coisas de duas formas. Eles podem representar descritivamente algum estado de coisas e, nesse caso, a forma proposicional reflete fielmente esse estado de coisas. Eles podem representar interpretativamente outra representação que também tenha uma forma proposicional (um pensamento, por exemplo) considerandose a semelhança entre as respectivas formas proposicionais. Em um nível mais básico, todos os enunciados representam um pensamento do falante/escritor e são metafóricos em algum grau. Eles equivalem a uma interpretação pública de um de seus pensamentos, que é ofertada ostensivamente, de modo que o ouvinte/leitor possa elaborar uma suposição interpretativa sobre a intenção informativa do falante/escritor. Assim, de um enunciado decorrem duas relações: entre sua forma proposicional e um pensamento do falante/escritor e entre esse pensamento e aquilo que esse pensamento está representando.

Para Sperber e Wilson (1995, p. 231; 2001, p. 342), em enunciados imperativos, há uma relação descritiva entre o pensamento do falante/escritor e um estado de coisas desejável, tanto do ponto de vista do falante/escritor (uma ordem, por exemplo), como do ponto de vista

RAUEN - Avaliação da habilidade de inferência... 
do ouvinte/leitor (um conselho, por exemplo). Mônica está propondo um acordo com Cebolinha. Mas para quem esse acordo é desejável?

Para que a criança consiga detectar essa sutileza, ela precisa fazer uma inferência com base em duas pistas imagéticas que se encontram no primeiro quadrinho. Nele, o que se pode perceber é que Mônica está sorrindo e Cebolinha está triste. A hipótese é a de que o acordo é benéfico para Mônica, mas não para Cebolinha. Veja-se:

$\mathrm{S}_{1}$ - Mônica propõe que Cebolinha pare de xingar Mônica agora (da explicatura do enunciado de Mônica);

$\mathrm{S}_{2}$ - Mônica está sorrindo (do estímulo visual);

$\mathrm{S}_{3}-\mathrm{S}_{1} \wedge \mathrm{S}_{2} \rightarrow \mathrm{S}_{4}$ (por modus ponens conjuntivo);

$\mathrm{S}_{4}$ - A proposta de Mônica provavelmente é boa para Mônica (conclusão implicada).

$\mathrm{S}_{5}$ - Cebolinha está triste (do estímulo visual);

$\mathrm{S}_{6}-\mathrm{S}_{1} \wedge \mathrm{S}_{5} \rightarrow \mathrm{S}_{7}$ (por modus ponens conjuntivo);

$\mathrm{S}_{7}-\mathrm{A}$ proposta de Mônica provavelmente é ruim para Cebolinha (conclusão implicada).

Em síntese, nessa possibilidade de interpretação da fala de Mônica, pode-se dizer que ela propôs ser desejável, provavelmente de seu ponto de vista, que se Cebolinha parar de xingá-la, então ela não lhe bateria mais e ainda the daria um beijo.

Uma vez conhecida a descrição da fala de Mônica, segue-se a reação de Cebolinha no segundo quadrinho. Ele volta a xingá-la de "Golducha e Baliguda" formulando uma sentença nominal, razão pela qual se passa direto da descrição linguística em (2a) para a descrição do ato de fala em (2b).

(2a) Sua Golducha e Baliguda;

(2b) CEBOLINHA XINGA MÔNICA DE SUA GORDUCHA E BARRIGUDA. 
O xingamento de Cebolinha permite gerar, entre outros efeitos, a confirmação da hipótese anterior de que a proposta de Mônica é ruim para Cebolinha.

$\mathrm{S}_{1}$ - Cebolinha xinga Mônica de gorducha e barriguda (do input linguístico);

$\mathrm{S}_{2}-\mathrm{S}_{1} \rightarrow \mathrm{S}_{3}$ (por modus ponens);

$\mathrm{S}_{3}$ - A proposta de Mônica era ruim para Cebolinha (confirmada).

A reação de Mônica é supostamente de desaprovação. Para compreendê-la, retome-se a proposição de Mônica, que se conforma na fórmula: $\mathrm{P} \rightarrow(\neg \mathrm{Q} \wedge \mathrm{R})$. Sua expectativa é a de que o comportamento de Cebolinha seja compatível com sua proposição $\mathrm{P}$, o que a autorizaria a cumprir as promessas $(\neg \mathrm{Q} \wedge \mathrm{R})$.

$\mathrm{P} \rightarrow(\neg \mathrm{Q} \wedge \mathrm{R})$ - Se Cebolinha parar de xingar Mônica, então Mônica não baterá mais em Cebolinha e dará um beijo em Cebolinha;

P - Cebolinha para de xingar Mônica;

$(\neg \mathrm{Q} \wedge \mathrm{R})$ - Mônica não baterá mais em Cebolinha e dará um beijo em Cebolinha.

Cebolinha, entretanto, ao voltar a xingá-la $(\neg \mathrm{P})$, sugere que ele prefere que ela volte a bater nele $(\mathrm{Q})$ e não o beije $(\neg \mathrm{R})$, e a criança, por sua vez, está autorizada a inferir que Mônica cumprirá essas promessas.

$\mathrm{P} \rightarrow(\neg \mathrm{Q} \wedge \mathrm{R})$ - Se Cebolinha parar de xingar Mônica, então Mônica não baterá mais em Cebolinha e dará um beijo em Cebolinha;

$\neg \mathrm{P}$ - Cebolinha não para de xingar Mônica;

$(\mathrm{Q} \wedge \neg \mathrm{R})$ - Mônica baterá mais em Cebolinha e não dará um beijo em Cebolinha. 
Vale destacar que para a criança chegar a essa interpretação, ela precisa conhecer o universo ficcional de Maurício de Sousa. Em especial, precisa conhecer as características das personagens em questão. Já se mencionou a suposição factual sobre o hábito de Cebolinha xingar Mônica. Agora se faz necessário, dada a idade das personagens, supor que Cebolinha prefere apanhar de Mônica a ser beijado por ela.

$S_{1}$ - Mônica propõe que se Cebolinha parar de xingar Mônica agora, então Mônica não baterá mais em Cebolinha depois e dará um beijo em Cebolinha depois (da explicatura do enunciado de Mônica);

$\mathrm{S}_{2}$ - Cebolinha xinga Mônica de gorducha e barriguda (do enunciado de Cebolinha);

$\mathrm{S}_{3}-\mathrm{S}_{1} \wedge \mathrm{S}_{2} \rightarrow \mathrm{S}_{4}$ (por modus ponens conjuntivo);

$\mathrm{S}_{4}$ - Cebolinha prefere apanhar de Mônica a ser beijado por Mônica (conclusão implicada).

Analisados os quadrinhos, entra em questão a proposição da vigésima questão da segunda edição de 2009 da Provinha Brasil. Veja-se:

(3a) Por que o Cebolinha ficou bravo com a Mônica?

(3b) (ficar x, y, QU-motivo)

(3c) POR QUE O CEBOLINHA FICOU BRAVO COM A MÔNICA?

(3d) O APLICADOR DESEJA SABER POR QUE CEBOLINHA FICOU BRAVO COM A MÔNICA?

O interessante, nessa questão, é que as respostas enumeram razões pelas quais o Cebolinha ficou bravo com a proposta da Mônica, sugerindo que o avaliador está interessado não somente na interpretação dos imputs linguísticos, mas na interpretação da imagem. Repare-se que a questão, em si mesma, aciona necessariamente a seguinte inferência: 
$\mathrm{S}_{1}$ - Cebolinha xingou Mônica de gorducha e barriguda (do input linguístico);

$\mathrm{S}_{2}-\mathrm{S}_{1} \rightarrow \mathrm{S}_{3}$ (por modus ponens);

$\mathrm{S}_{3}$ - Cebolinha ficou bravo com Mônica (conclusão implicada).

Segundo Sperber e Wilson, perguntas são interpretações de pensamentos desejáveis, ou seja, são interpretações de respostas que o falante/escritor consideraria como relevantes caso fossem verdadeiras. A hipótese em jogo é a de que o ouvinte/leitor de um enunciado interrogativo recupera sua forma lógica e a integra numa descrição com a forma "O falante/escritor pergunta QU-P", em que QU-P é uma pergunta indireta. As alternativas de resposta são, desse modo, complementações de enunciados declarativos que satisfariam a relevância, caso verdadeiros. No caso de perguntas de exame, a resposta será relevante não tanto em função de seu conteúdo, mas como evidência indireta que ela fornece em relação ao domínio que a criança demonstra de suas capacidades inferenciais

Vejam-se as respostas, encaixando-as nas respectivas proposições.

(4a) (Alternativa A) O Cebolinha ficou bravo com a Mônica porque a Mônica deu um susto no Cebolinha;

(4b) (Alternativa B) O Cebolinha ficou bravo com a Mônica porque a Mônica queria bater no Cebolinha;

(4c) (Alternativa C) O Cebolinha ficou bravo com a Mônica porque o Cebolinha não gostava de apanhar da Mônica;

(4d) (Alternativa D) O Cebolinha ficou bravo com a Mônica porque o Cebolinha não queria beijar a Mônica.

A análise dos quadrinhos desenvolvida até o momento sugere que a alternativa D "porque ele não queria beijar a Mônica" está correta. Para se chegar a essa resposta, basta mais uma inferência: aquela que, partindo das preferências de Cebolinha de apanhar a ser beijado, leva à conclusão de que ele não queria ser beijado. 
$S_{1}$ - Cebolinha prefere apanhar de Mônica a ser beijado por Mônica (suposição factual);

$\mathrm{S}_{2}-\mathrm{S}_{1} \rightarrow \mathrm{S}_{3}$ (por modus ponens);

$\mathrm{S}_{3}$ - Cebolinha não quer ser beijado por Mônica (conclusão implicada).

Para tirar a prova é só reverter a inferência:

$S_{1}$ - Mônica propõe que se Cebolinha parar de xingar Mônica agora, então Mônica não baterá mais em Cebolinha depois e dará um beijo em Cebolinha depois (da explicatura do enunciado de Mônica);

$\mathrm{S}_{2}$ - Cebolinha não quer ser beijado por Mônica (suposição factual);

$\mathrm{S}_{3}-\mathrm{S}_{1} \wedge \mathrm{S}_{2} \rightarrow \mathrm{S}_{4}$ (por modus ponens conjuntivo);

$\mathrm{S}_{4}-$ Cebolinha xinga Mônica (conclusão implicada).

Conforme o gabarito de correção da segunda edição de 2009 da Provinha Brasil, a alternativa correta é justamente a alternativa D. Contudo, poderia outra opção de resposta ser plausível para essa questão?

Veja-se, em primeiro lugar, a alternativa C "porque ele não gostava de apanhar dela”. Essa opção não é correta, porque Cebolinha voltou a xingar Mônica, sugerindo que ele preferiria apanhar de Mônica a beijá-la. Contudo, o motivo de sua raiva justamente não estaria em ser obrigado a escolher o mal menor?

O que está em jogo aqui são os desejos das duas personagens. Cebolinha supostamente preferiria continuar a xingar Mônica, não apanhar dela e não ser beijado por ela. A proposta de Mônica o coloca na contingência de escolher uma de duas alternativas supostamente ruins para ele. Aceitando a proposta, ele se livra da surra, mas tem de parar de xingá-la e ainda ser beijado por ela. Rejeitando a proposta, como de fato ele o faz, ele pode continuar a xingá-la, livra-se do beijo, mas terá de apanhar novamente. Eis um bom motivo para ficar bravo, pois ele, de fato, não gostaria de apanhar novamente da Mônica. 
Antes de tratar da alternativa B "porque ela queria bater nele", é preciso discutir níveis de sofisticação das capacidades inferenciais humanas. Wilson (2004) sugere que o desenvolvimento das competências pragmáticas pelas crianças pequenas, aqui se referindo a crianças menores do que aquelas do segundo ano do ensino fundamental, parece seguir estágios regulares, cada estágio envolvendo enganos característicos. Desse modo, se expectativas de relevância criadas por enunciados podem ser mais ou menos sofisticadas, é razoável assumir que crianças começam com uma expectativa ingênua da relevância ótima real e simplesmente escolhem a primeira interpretação que é otimamente relevante a elas. Em seguida, as crianças poderiam desenvolver uma expectativa mais sofisticada da relevância ótima tentada, procurando a primeira interpretação que o falante poderia ter pensado como otimamente relevante para elas. Finalmente, elas poderiam tornarse capazes de formar uma expectativa plenamente sofisticada de relevância ótima pretendida e escolher a primeira interpretação que o falante poderia ter pensado que pareceria otimamente relevante a elas. Segundo a autora, esse estágio envolveria uma habilidade maior de pensar sobre os pensamentos de outros, ajustando-se com o que se define como "teoria de mente".

A alternativa B "porque ela queria bater nele", concebida como distrator, é uma inferência factível, embora mais complexa. Nessa alternativa, o que se capta não é a inferência primeira de que o xingamento evita o beijo, mas a inferência mais sofisticada de que Mônica está propondo ardilosamente o beijo porque antecipa a reação de Cebolinha, ou seja, ela antecipa a suposição de que Cebolinha prefere apanhar a receber um beijo dela. Jogando com essa suposição, ela propõe justamente o que Cebolinha rejeita para conseguir o que quer: bater nele.

$\mathrm{Na}$ interpretação-alvo que sustenta a alternativa D como correta, três suposições têm de ser aceitas como factuais, e a proposta da Mônica tem de ser considerada como sincera. Nesse caso, Mônica não quer mais ser xingada e, com sinceridade, promete parar de bater nele e ainda beijá-lo:

$$
\begin{aligned}
& \mathrm{S}_{1} \text { - Mônica não quer ser xingada por Cebolinha; } \\
& \mathrm{S}_{2} \text { - Mônica não quer bater em Cebolinha; } \\
& \mathrm{S}_{3}-\text { Mônica quer beijar Cebolinha. }
\end{aligned}
$$


Entretanto, por hipótese, imagine-se que a proposta é ardilosa, justamente porque é difícil acreditar que Mônica não queira bater mais em Cebolinha. Isso autorizaria a seguinte cadeia de inferências:

$S_{1}$ - Mônica quer bater em Cebolinha (suposição factual);

$\mathrm{S}_{2}$ - Cebolinha precisa xingar Mônica para Mônica bater em Cebolinha (suposição factual);

$\mathrm{S}_{3}-\mathrm{S}_{1} \wedge \mathrm{S}_{2} \rightarrow \mathrm{S}_{4}$ (por modus ponens conjuntivo);

$\mathrm{S}_{4}$ - Mônica precisa fazer Cebolinha xingar Mônica (conclusão implicada);

$\mathrm{S}_{5}$ - Cebolinha não quer ser beijado por Mônica (suposição factual);

$\mathrm{S}_{6}-\mathrm{S}_{4} \wedge \mathrm{S}_{5} \rightarrow \mathrm{S}_{7}$ (por modus ponens conjuntivo);

$\mathrm{S}_{7}$ - Mônica propõe parar de bater e beijar Cebolinha caso ele não a xingue mais (da explicatura do enunciado de Mônica);

$\mathrm{S}_{8}$ - Cebolinha preferirá xingar Mônica a ser beijado por Mônica (suposição factual);

$\mathrm{S}_{9}-\mathrm{S}_{7} \wedge \mathrm{S}_{8} \rightarrow \mathrm{S}_{10}$ (por modus ponens conjuntivo);

$\mathrm{S}_{10}-$ Cebolinha xingará Mônica (conclusão implicada);

$\mathrm{S}_{11}-\mathrm{S}_{10} \rightarrow \mathrm{S}_{12}$ (por modus ponens);

$\mathrm{S}_{12}$ - Mônica baterá em Cebolinha (conclusão implicada).

Uma criança poderia alcançar essa cadeia de inferência mais complexa ou essa seria uma espécie de teoria da conspiração. Para chegar a essa conclusão, as crianças precisam conhecer o universo ficcional da obra de Maurício de Sousa. Não será difícil encontrar nos quadrinhos casos em que Cebolinha, por exemplo, elabora ardis para irritar Mônica. Assim, Mônica bolar um ardil para bater em Cebolinha não seria um absurdo.

Do ponto de vista não verbal, contra essa interpretação, pode-se destacar a análise da feição de Mônica aparentemente triste ou desapontada no segundo quadrinho. Todavia, a favor dessa interpretação, qual seria a motivação de o coelhinho de pelúcia Sansão estar nas costas de Mônica nos dois quadrinhos? Uma hipótese consistente seria a de reforçar o caráter ardiloso da proposta. 
$S_{1}$ - Mônica sempre bate em Cebolinha com o coelhinho de pelúcia Sansão (suposição factual);

$\mathrm{S}_{2}$ - Mônica está escondendo o coelhinho de pelúcia Sansão nas costas (do input visual);

$\mathrm{S}_{3}-\mathrm{S}_{1} \wedge \mathrm{S}_{2} \rightarrow \mathrm{S}_{4}$ (por modus ponens conjuntivo);

$\mathrm{S}_{4}$ - Mônica pode bater em Cebolinha com o coelhinho de pelúcia Sansão (conclusão implicada);

$\mathrm{S}_{5}-\mathrm{S}_{4} \rightarrow \mathrm{S}_{6}$ (por modus ponens);

$\mathrm{S}_{6}$ - Mônica está enganando Cebolinha com a proposta (conclusão implicada);

$\mathrm{S}_{7}-\mathrm{S}_{6} \rightarrow \mathrm{S}_{8}$ (por modus ponens);

$\mathrm{S}_{8}$ - Mônica quer bater em Cebolinha com o coelhinho de pelúcia Sansão (conclusão implicada).

Seja como for, a hipótese de que Cebolinha ficou bravo porque Mônica queria bater nele, considerada errada no gabarito, pode ser correta e compete com a resposta-alvo. Como antecipa a Teoria da Relevância, a primeira interpretação consistente com o princípio de relevância é a interpretação relevante, e nenhuma outra será considerada. Desse modo, a opção pelas alternativas D ou B vai depender de qual das duas cadeias de inferência será a primeira a ser considerada relevante pela criança.

Por fim, há a alternativa A "porque ela deu um susto nele". Em princípio, essa alternativa é esdrúxula. Todavia, basta retomarmos a suposição factual de que Cebolinha não quer ser beijado por Mônica, aliás, necessária para justificar sua opção por xingá-la, para inferir que a proposta de Mônica pode ser interpretada como um susto. Veja-se

$\mathrm{S}_{1}$ - Mônica propõe beijar Cebolinha caso ele pare de xingá-la (da explicatura do enunciado de Mônica);

$\mathrm{S}_{2}$ - Cebolinha tem medo de ser beijado por Mônica (suposição factual);

$\mathrm{S}_{3}-\mathrm{S}_{1} \wedge \mathrm{S}_{2} \rightarrow \mathrm{S}_{4}$ (por modus ponens conjuntivo);

$\mathrm{S}_{4}$ - Mônica deu um susto em Cebolinha (conclusão implicada);

$\mathrm{S}_{5}-\mathrm{S}_{2} \wedge \mathrm{S}_{4} \rightarrow \mathrm{S}_{6}$ (por modus ponens conjuntivo);

$\mathrm{S}_{6}$ - Cebolinha ficou bravo porque Mônica deu um susto em Cebolinha (conclusão implicada).

RAUEN - Avaliação da habilidade de inferência... 


\section{CONSIDERAÇÕES FINAIS}

Os achados da dissertação de Nazário (2010) revelaram uma dispersão nas respostas de dez alfabetizadoras para a vigésima questão da segunda edição da Provinha Brasil. Nessa questão, somente quatro docentes identificaram a alternativa $\mathrm{D}$ (resposta-alvo), três optaram pela alternativa B, uma optou pela alternativa C, uma optou pelas alternativas $\mathrm{B}$ e $\mathrm{C}$ e uma optou por todas as alternativas (as duas últimas justificaram a opção por mais de uma resposta, porque, segundo elas, o texto era confuso e várias alternativas estavam certas).

A análise da questão, das opções de resposta e do desempenho das docentes no estudo de Nazário (2010) coloca em xeque a alternativa $\mathrm{D}$ como única resposta correta. De fato, para a criança considerar essa alternativa, ela precisa desenvolver uma cadeia complexa de inferências que levem a crer que Cebolinha xingou Mônica porque ele não queria que ela o beijasse. Contudo, a proposta de Mônica poderia ter sido ardilosa e, numa cadeia de inferências mais complexa, ela propôs o beijo apostando na rejeição da proposta. Como a rejeição implica novo xingamento, que autorizaria uma nova surra, Cebolinha pode muito bem ter ficado bravo por ter detectado esse ardil, como sugere a alternativa B. Ele também poderia ter ficado bravo por ter sido vítima de uma armadilha da qual não sai sem fazer algo que não quer. $O$ fato de ele preferir apanhar a ser beijado não elimina o fato de ele não gostar de apanhar, como sugere a alternativa $\mathrm{C}$, apenas esse é um mal menor. Por fim, a mera menção à possibilidade de ser beijado pode funcionar como um susto, como sugere a alternativa A, e o susto pode ser razão suficiente para deixá-lo bravo.

Esse estudo põe em evidência a dificuldade de se elaborarem alternativas para questões que testem inferências. As alternativas precisam ser ao mesmo tempo incorretas e, de algum modo, concorrerem com a resposta correta. O problema é que o elaborador da questão corre o risco de subestimar a capacidade inferencial das crianças. Elas podem jogar com a força das suposições de diferentes maneiras. Por exemplo, a interpretação de que Mônica teria assustado Cebolinha com sua proposta sobrevaloriza a força com que confia na suposição de que Cebolinha não quer ser beijado (ele teria pavor disso). Além disso, elas podem optar por diferentes cadeias de inferências. Certamente esse 
seria o caso daquelas que interpretaram a proposta de Mônica como um ardil ou como uma armadilha. Seja como for, atribuir erro a interpretações alternativas, inclusive aquelas que se revelam mais complexas, é um aspecto que precisa ser evitado em futuras edições da Provinha Brasil.

\section{REFERÊNCIAS}

BRASIL. Ministério da Educação. Ensino fundamental de nove anos: orientações para a inclusão de crianças de seis anos de idade. Brasília: FNDE, Estação Gráfica, 2006.

BRASIL. Ministério da Educação. Instituto Nacional de Estudos e Pesquisas Educacionais Anísio Teixeira. Orientações para Secretarias de Educação. Brasília: Inep, 2009.

BRASIL. Ministério da Educação. Secretaria de Educação Básica. Próletramento: Programa de formação continuada dos anos/séries iniciais do ensino fundamental: alfabetização e linguagem. Brasília: Ministério da Educação, Secretaria de Educação Básica, 2007.

NAZÁRIO, F.G. Competências para a análise crítica de questões da

Provinha Brasil: estudo de caso com docentes alfabetizadores de um município catarinense. 2010. 110f. Dissertação (Mestrado em Ciências da Linguagem)Programa de Pós-graduação em Ciências da Linguagem, Universidade do Sul de Santa Catarina, 2010.

RAUEN, F. J. Inferências em resumo com consulta ao texto de base: estudo de caso com base na Teoria da Relevância. Linguagem em (Dis)curso - LemD, Tubarão, v. 5, n. esp., p. 33-57, 2005.

SILVEIRA, J. R. C. da; FELTES, H. P. de M. Pragmática e cognição: a textualidade pela relevância e outros ensaios. 3. ed. Porto Alegre: Edipucrs, 2002.

SPERBER, D.; WILSON, D. Relevância: comunicação e cognição. Lisboa: Fundação Galouste Gulbenkian, 2001.

SPERBER, D.; WILSON, D. Relevance: communication \& cognition. 2nd. ed. Oxford: Blackwell, 1995. [1st. ed. 1986].

WILSON, D. Pragmatic theory. London: UCL Linguistics Dept, 2004. Disponível em: http://www.phon.ucl.ac.uk/home/nick/pragtheory/. Acesso em: 15 mar. 2005.

RAUEN - Avaliação da habilidade de inferência... 


\section{Recebido em 10/03/11. Aprovado em 01/06/11.}

Title: Evaluation of inference skills in reading: a case study with one question of "Provinha Brasil" Author: Fábio José Rauen

Abstract: Provinha Brasil aims to evaluate the Brazilian students' literacy level in the 2nd year of elementary school. In 2009, there were two editions of Provinha Brasil: at the beginning of the school year, in order to assess the literacy process, and at the end of the school year, in order to compare the students' performance with the first evaluation and to identify progresses and limitations. Among the skills under evaluation, the ability to infer information based on text reading stands out. In the 2009 second edition, based on a comic strip by Mauricio de Sousa, the twentieth question is related to this skill descriptor. Motivated by the dispersion of responses to this question by ten literacy teachers in Nazario's 2010 dissertation, proposition and response options of the twentieth question were analyzed based on Relevance Theory. It is argued that there are difficulties for the development of alternative options to inferential questions, since more sophisticated inferences and different degrees of strength of cognitive assumptions may be at stake.

Keywords: Cognition. Inference. Relevance. Relevance theory. Provinha Brasil.

Titulo: Evaluación de la habilidad de inferencia en lectura: estudio de caso con una cuestión de la "Provinha Brasil"

Autor: Fábio José Rauen

Resumen: Provinha Brasil tiene como objetivo evaluar el nivel de alfabetización de los estudiantes brasileños en el $2^{\circ}$ año de la escuela primaria. En 2009, bubo dos ediciones de Provinha Brasil: al inicio del año escolar, a fin de evaluar el proceso de alfabetización, y al final del año escolar, con el fin de comparar el rendimiento de los estudiantes con la primera evaluación e identificar avances y limitaciones. Entre las competencias en evaluación, se destaca la de inferir la información basada en la lectura de textos. En la segunda edición de 2009, con base en una tira cómica de Mauricio de Sousa, la vigésima cuestión fue relacionada con este descriptor de habilidad. Motivados por la dispersión de las respuestas a esta pregunta por diez profesoras de alfabetización en la disertación de Nazario (2010), en esto artículo, fueron analizados con base en la Teoría de la Relevancia la propuesta y las opciones de respuesta de esa cuestión. Basándose en los resultados, se destacan las dificultades para el desarrollo de opciones alternativas a las preguntas de inferencia, ya que inferencias más sofisticadas y diferentes grados de fuerza de las suposiciones cognitivas pueden estar en juego.

Palabras Clave: Cognición. Inferencia. Relevancia.Teoría de la relevancia. Provinha Brasil.

Linguagem em (Dis)curso, Tubarão, SC, v. 11, n. 2, p. 217-240, maio/ago. 2011 